\title{
Rio Místico / Mystic River (2003): "Hay hilos en nuestras vidas. Si uno tira de ellos, todo lo demás se ve afectado"
}

\author{
Maritza BOCIC1, Angélica VARGAS1,2 \\ ${ }^{1}$ Universidad de Santiago de Chile (Chile). ${ }^{2}$ Hospital Félix Bulnes (Chile). \\ Autor para correspondencia: Maritza Bocic. Correo electrónico: dra.maritzabocic@gmail.com \\ Recibido el 1 de junio de 2018; aceptado el 18 de junio de 2018.
}

Cómo citar este artículo: Bocic M, Vargas A. Rio Místico / Mystic River (2003): "Hay hilos en nuestras vidas. Si uno tira de ellos, todo lo demás se ve afectado". Rev Med Cine [Internet] 2019;15(2): 67-71.

DOI: http://dx.doi.org/10.14201/rmc20191526771

\begin{abstract}
Resumen
En nuestro taller de cine, actividad docente semanal para internos de la carrera de medicina, hemos elegido esta película Rio Místico, a través de ella hacemos un análisis del impacto en el desarrollo de la personalidad y los vínculos. Clint Eastwood nos relata la historio de tres amigos, que presencia el rapto y abuso sexual de uno de ellos, 25 años después los personajes se encuentran por otro hecho trágico, revelándose el que ocurrió hace 25 años. El tiempo y el silencio marco y determino la vida de sus protagonistas.
\end{abstract}

Palabras clave: Río Místico, abuso sexual, desarrollo de la personalidad, vínculos, psicopatología.

\section{Mystic River (2003): "There are threads in our lives. If one pulls them, everything else is affected"}

\section{Summary}

In our film workshop, a weekly teaching activity for interns in the medical career, we have chosen this movie Mystic River, through which we analyze the impact on the development of the personality and the links of sexual abuse in childhood. Clint Eastwood tells the story of three friends, who witness the abduction and sexual abuse of one of them, 25 years later perrsonajes are found by another tragic fact, revealing what happened 25 years ago. Time and silence frame and determine the life of its protagonists.

Keywords: Mystic River, Sexual abuse, Development personality, Links, Psychopathology. 


\section{Ficha técnica}

Título original: Mystic River.

País: Estados Unidos.

Año: 2003.

Director: Clint Eastwood.

Música: Clint Eastwood.

Fotografía: Tem Sterm.

Montaje: Joel Cox.

Guion: Brian Helgelan. Dennis Lehane (novela). Intérpretes: Sean Penn, Kevin Bacon, Tim Robbins, Laurence Fishburne, Laura Linney, Marcia Gay Harden, ...

Duración: 137 minutos.

Género: drama.

Idioma original: inglés.

Productoras: Ville Roadshow picture, Mal Paso Sinopsis: En 1975 Jimmy, Sean y Dave son tres niños que jugaban hockey en la calle de su barrio en Boston. Su vida da un vuelco cuando son interceptados por un falso policía, quien obliga a Dave a subirse a un auto. El niño es mantenido prisionero en un sótano y es abusado sexualmente por sus captores durante cuatro días, cuando logra escapar a través de un bosque; pero el niño que salió de aquel sótano ya no era Dave. Veinticinco años más tarde, los amigos ya se han distanciado y sus vidas han tomados rumbos distintos. Jimmy es un ex convicto, dueño de la tienda del barrio de la infancia, Dave está casado con la prima de la esposa de Jimmy y vive con el peso del secreto de su trauma, y Sean es un detective de la brigada de homicidios de la policía de Massachusetts. El destino los reúne cuando la hija adolescente de Jimmy es brutalmente asesinada. Comienza a desarrollarse una red de intrigas que lleva a Jimmy a pensar que Dave es el culpable del homicidio, por lo que decide tomar la justicia por sus propias manos. Muy tarde se da cuenta de que estaba equivocado.

\section{Enlaces:}

https://www.imdb.com/title/tt0327056

https://www.filmaffinity.com/es/film121917.html

\section{Tráiler en español}

\section{Introducción}

En 1975 Jimmy, Sean y Dave son tres niños que jugaban hockey en la calle de su barrio en Boston. Su vida da un vuelco cuando son interceptados por un falso

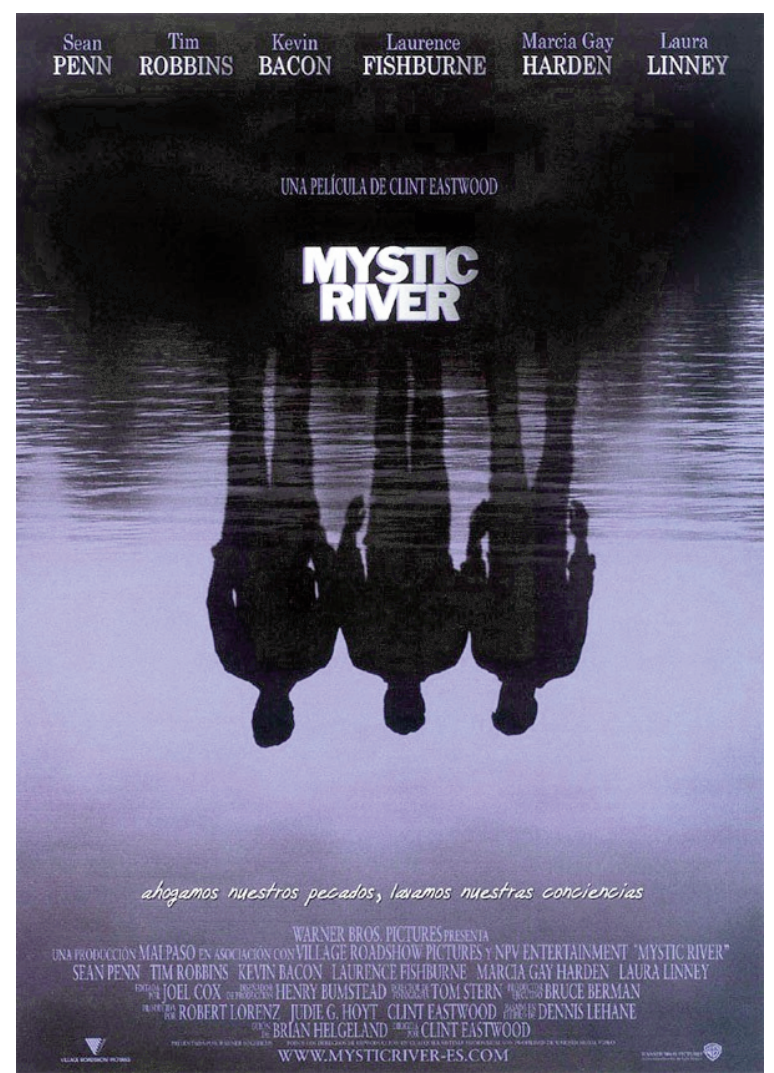

policía, quien obliga a Dave a subirse a un auto. El niño es mantenido prisionero en un sótano y es abusado sexualmente por sus captores durante cuatro días, cuando logra escapar a través de un bosque; pero el niño que salió de aquel sótano ya no era Dave.

Veinticinco años más tarde, los amigos ya se han distanciado y sus vidas han tomados rumbos distintos. Jimmy es un exconvicto, dueño de la tienda del barrio de la infancia, Dave está casado con la prima de la esposa de Jimmy y vive con el peso del secreto de su trauma, y Sean es un detective de la brigada de homicidios de la policía de Massachusetts. El destino los reúne cuando la hija adolescente de Jimmy es brutalmente asesinada. Comienza a desarrollarse una red de intrigas que lleva a Jimmy a pensar que Dave es el culpable del homicidio, por lo que decide tomar la justicia por sus propias manos. Muy tarde se da cuenta de que estaba equivocado.

Eastwood nos presenta un thriller que ahonda en la novela de Dennis Lehane

La historia la interpretan Sean Penn, Tim Robbins y Kevin Bacon en la zona de Boston donde el Rio Mystic baña las nobles casas de las familias que despiertan con un terrible suceso. 
Clint Eastwood, director de Mystic River, se destaca por su calidad técnica y narrativa, donde las imágenes, banda sonora, fotografía y dirección de arte se conjugan para entregar retratos de la condición humana, en Río Místico podemos apreciar con toda claridad emociones que nos conmueven como la desorientación, la pérdida, el dolor, el estrechamiento de las perspectivas vitales a golpe de circunstancia.

En este filme el tiempo es un personaje, ese destructor que guarda secretos, historias que carcomen al individuo hasta que la declara y los otros la reconocen.

En el escenario de Río Místico el tiempo hace su trabajo de demolición de forma metódica y sistemática, exhibiendo impúdicamente su capacidad "disolutoria", marcando las pautas y determinando las circunstancias de los personajes. El tiempo se insinúa cuando los niños escriben sus nombres y dicen casi como una condena para siempre, así fue: aquel hecho casual marcó la vida de cada uno de esos niños, de los tres amigos de la infancia que el tiempo y las circunstancias los alejan.

Magnífico trabajo de director y guionista para mostrarnos el "íter" de los protagonistas desde su infancia hasta su edad adulta, cómo llegaron a ser lo que hoy son: se nos devela explícitamente en el caso de Jimmy, pero no en cuanto a Dave Boyle y Sean Devine, cuya trayectoria vital hasta el punto en que arranca el episodio central de la trama permanece en la más absoluta de la oscuridad.

Lo suponemos en el caso de Dave Bole, su estructura y lenguaje corporal, su andar quieto, su introspección, nos hace empatizar con el dolor que carga, sin reparación y Sean Devine durante toda la película es un enigma.

Eastwood, es un maestro para entregar la psicología de sus personajes a través de la imagen narrativa, el poder de sugerencia de la vigorosa puesta en escena de Eastwood es tal que uno absorbe los hechos uno tras otro, sin asumir del todo la complejidad de los mismos hasta que se reflexiona sobre ellos. Así este Film se convierte en un interesante elemento para la docencia y reflexión Clínica.

Un buen ejemplo de ello es la secuencia en el balcón durante el funeral de Katie en el que Dave y Jimmy son encuadrados en el plano con un suave contrapicado y según Jimmy comienza a abrirse a su amigo de infancia y a asumir la irreparable pérdida que para él supone la muerte de Katie, Eastwood se acerca más y más a ambos, de tal forma que uno entra de lleno tanto en el enorme dolor de un Sean Penn y la empatía que Dave siente hacia su dolor. El plano de Jimmy y Sean ya adultos, viendo alejarse de nuevo en la misma calle el coche que veinte años antes se llevó al verdadero Dave de sus vidas.

La dirección de arte nos entrega un entorno físico enormemente apropiado, Boston ordenado, tan europeo, con su sol en sordina, la consecuente luz mortecina, captada de manera sublime, así como el tiempo es un personaje también es el entorno: la calle, el bosque.

Mystic River es entre otras muchas cosas, una película que nos habla, de aquello que los terapeutas sabemos con una certeza cotidiana de cómo un hecho violento acaecido veinte años atrás marca indeleblemente las vidas de las personas y de aquellos que les rodean hasta tal punto que pese al tiempo transcurrido y el deseo por parte de todos ellos de continuar con sus vidas se reaparece una y otra vez aun sin nombrarlo.

Hemos elegido esta película para abordar este tema, de los eventos traumáticos, del abuso y su presencia en la psicopatología de la vida adulta.

Lo vemos en la metáfora del nombre incompleto de Dave en el cemento, su terrible significado cuando asistimos con horror a la experiencia traumática del rapto y la posterior violación de Dave, una agresión que trunca la amistad de los tres niños. En una inteligente lectura del personaje, Eastwood logra mostrar en imágenes esa metáfora, la disociación causada por el trauma: el personaje se ve a sí mismo fragmentado en dos, incapaz de conciliar su yo actual con el de ese niño que no pudo escapar de sus captores y al que ve como alguien lejano, distinto a él mismo. Dave se ve a sí mismo como uno de esos vampiros que mira en el televisor, como una bestia contaminada, marcada, enferma.

\section{Examen mental de Dave Boyle}

Hombre, de mediana edad, se ve mayor que su edad cronológica (en comparación con sus dos examigos). Lleva una vestimenta adecuada a la época del año, de colores opacos, sin características destacables.

La actitud suele ser reservada, con tendencia al silencio; llama la atención que al ser interrogado por la policía actúa con mucha seguridad, sin demostrar nerviosismo ni miedo. El contacto visual es escaso, pero lo realiza con gran intensidad en momentos de tensión, como en el interrogatorio, cuando desesperado vuelve lleno de sangre la noche que murió Katie. 
Con frecuencia se observa cabizbajo, con los hombros caídos. Los movimientos tienen una velocidad conservada, pero son poco enérgicos. La expresión facial tiende a la tristeza y tiene escasa variabilidad (hipomímia).

En Dave se observa una tristeza vital que traspasa la pantalla, en general aparece distante, pero tiene momentos de marcada labilidad emocional, especialmente cuando experimenta situaciones relativas a su experiencia traumática, incluso con episodios de agresividad y violencia (como el ataque al pederasta). Destaca que, en el momento en que Dave le cuenta a su esposa lo sucedido en su infancia, tiene un momento de clara disociación ideoafectiva cuando suelta una carcajada que termina en llanto.

El lenguaje es fluente, con velocidad conservada, pero escaso en vocabulario (con tendencia a las respuestas monosilábicas) y en temas tratados; en general es notificativo, pero se vuelve comunicativo al contarle a su esposa respecto a su experiencia traumática o al contarle cuentos a su hijo (los cuales también hacen referencia a este hecho). En esta primera situación Dave se refiere a sí mismo en tercera persona; "Dave era el niño que escapó de los lobos (...) No sé quién salió de ese sótano, pero estoy seguro de que no era Dave".

No presenta alteraciones gramaticales ni en la articulación de las palabras

El pensamiento de Dave en general no presenta claras alteraciones del curso formal, la velocidad también parece conservada. En el momento de la confesión a su esposa aparecen pararrespuestas (al preguntarle respecto a lo sucedido la noche del asesinato, cuenta su experiencia en el auto y el sótano) y cierta disgregación, en concordancia con el contenido del relato.

También destacan momentos de flashbacks, como de los hombres en el auto, el sótano y la huida por el bosque; en un momento Dave confiesa "Ya no puedo confiar en mi mente".

Difícil de evaluar la conciencia de enfermedad con los datos aportados por la película, destaca el momento en que llega a su casa en la noche del asesinato y confiesa a su mujer "I think I fucked up", juzgando como un error el haber atacado al pederasta. Reconoce hasta cierto punto que no se encuentra bien, pero no queda claro cuál es la profundidad de este reconocimiento.

La conciencia en general no presenta alteraciones, pero el ataque al pederasta parece haber ocurrido en un contexto de oscurecimiento de conciencia, como un estado crepuscular.

\section{Diagnóstico según CIE10}

\section{Trastorno por estrés postraumático}

Dave presenta momentos de reexperimentación del hecho traumático (flashbacks, reactividad psicológica a elementos recordatorios) con un rango restringido de afectos y aislamiento social; además de irritabilidad y reacciones violentas.

\section{Diagnósticos diferenciales}

También se podría plantear la posibilidad de una transformación persistente de la personalidad tras experiencia catastrófica, pero al haber ocurrido el hecho traumático en la infancia, cuando aún la personalidad está en desarrollo, sería quizás más correcto llamarlo un trastorno del desarrollo de la personalidad; esto, pues desconocemos la vulnerabilidad personal previa y no podemos saber cómo hubiese sido la personalidad adulta si los hechos vitales hubiesen ocurrido de otro modo.

El diagnóstico de trastorno de la personalidad con rasgos antisociales podría plantearse, pero pierde validez cuando Dave expresa culpa frente a la acción violenta cometida, tampoco hay justificación de sus acciones ni falta de empatía francas.

Otro diagnóstico posible sería el de trastorno explosivo intermitente, pero este supone una agresividad desproporcionada al estímulo, lo que es difícil de establecer en este caso, y además dichas acciones parecen en un contexto de un desorden que abarca varios aspectos, más allá del control de impulsos.

\section{Abuso Sexual}

A través de este film queda muy claro como un abuso o un hecho traumático aún mayor como fue secuestro y abuso sexual de Dave marca no solo al individuo sino también a su entorno, determina las características psicológicas de los involucrados, aquellos que no fueron abusados, los que callaron.

El silencio y no revelar la verdad, entendiéndose esta como una verdad socialmente aceptada por otros hace imposible la reparación.

El abuso sexual en la infancia tiene múltiples y devastadoras consecuencias en el desarrollo de los 
niños. Hay, en primer lugar, una distorsión de la imagen de sí mismos, de la autovaloración, de la confianza en sí mismos y en otros. El juicio y sentido de la realidad se alteran, se siente culpa respecto a la posible participación en el propio abuso, generando sentimientos depresivos expresados como auto o heteroagresión.

Esta rabia sirve para lograr un distanciamiento psíquico de los otros, que son percibidos como amenazantes, lo cual resulta en una pérdida del soporte social a largo plazo ${ }^{1}$. Hay una tendencia al uso de mecanismos disociativos con el fin de la auto-protección.

También hay una clara alteración de la relación con otros, con quienes el niño tiende a repetir esta situación de abuso, desencadenando una marcada alteración del vínculo (sobre todo si el abusador es un familiar o conocido, "Quien me ama, me daña")2.

Lo anterior ha sido sistematizado por Ibaceta en su revisión del año 20073:

\footnotetext{
- Sexualización traumática: expresada como excesiva preocupación por cuestiones sexuales, erotización de las relaciones, promiscuidad y repetición compulsiva de conductas sexuales, o como inhibición y rechazo a la propia sexualidad.
}

- Traición: esto ocurre cuando el agresor tiene un vínculo previo con el niño, generando una sensación de desprotección y vulnerabilidad que puede generar relaciones de dependencia emocional intensa, o de una dificultad en la manera de vincularse, como desconfianza u hostilidad generalizadas.

\begin{abstract}
- Indefensión: hay una pérdida de la sensación de autonomía y control respecto a las propias conductas, generando miedo y ansiedad ante la imposibilidad de controlar lo que ocurre. Estudios demuestran que las personas, especialmente hombres, que han sido abusadas sexualmente en la infancia presentan 15 veces mayor riesgo de suicidio y 45 veces mayor riesgo de perpetrar violencia doméstica ${ }^{4}$.
\end{abstract}

\begin{abstract}
- Estigmatización: la autoimagen se construye en base a la sensación de culpa y vergüenza, se ven a sí mismos como distintos a otros, y la posibilidad de ser rechazados los obliga a mantener en secreto sus vivencias.
\end{abstract}

Esta conformación de la identidad lleva a que las víctimas de abuso sexual en la infancia presenten rasgos de personalidad narcisista o antisocial y mayor incidencia de trastorno de personalidad borderline, histriónico o dependiente ${ }^{5}$.

Asimismo, otros estudios han demostrado asociación entre abuso sexual infantil y desarrollo de trastornos psicóticos con un odds ratio cercano a 3 , siendo este riesgo significativo incluso al controlar la influencia de factores genéticos. Lo anterior tendría sus fundamentos en el cambio, tanto en el sistema inmune como en la respuesta al estrés, influyendo en estructuras como el hipocampo y la amígdala, asociado a la sensibilización del sistema dopaminérgico mesolímbico que los eventos traumáticos producen en el sistema nervioso del niño ${ }^{6}$.

A largo plazo, el abuso sexual en la infancia también ha sido relacionado con un mayor riesgo de patologías como la obesidad, trastornos autoinmunes, trastornos de la conducta alimentaria y adicciones 7,8 .

\section{Agradecimientos}

A la valentía del Dr James Hamilton que permitió abrir los procesos de reparación de muchos.

\section{Referencias}

1. Sperry DM, Widom CS. Child Abuse and Neglect, Social Support, and Psychopathology in Adulthood: A Prospective Investigation. Child Abuse Negl. 2013;37(6):415-25.

2. Almonte V. C. Psicopatología infantil y de la adolescencia. Santiago de Chile: Mediterráneo; 2006. 607 p.

3. Ibaceta Watson F. Agresión Sexual en la Infancia y Viaje al Futuro: Clínica y Psicoterapia en la Edad Adulta. Ter Psicológica. 2007;25(2):189-98.

4. Perepletchikova F, Kaufman J. Emotional and behavioral sequelae of childhood maltreatment. Curr Opin Pediatr. 2010;22(5):610-5.

5. N. Pereda, D. Gallardo-Pujol, R. Jiménez. Trastornos de personalidad en víctimas de abuso sexual infantil. [Internet]. [citado 31 de julio de 2014].

6. Van Winkel R, van Nierop M, Myin-Germeys I, van Os J. Childhood trauma as a cause of psychosis: linking genes, psychology, and biology. Can J Psychiatry Rev Can Psychiatr. 2013;58(1):44-51.

7. Wilson DR. Health Consequences of Childhood Sexual Abuse. Perspect Psychiatr Care. 2010;46(1):56-64.

8. Min MO, Minnes S, Kim H, Singer LT. Pathways linking childhood maltreatment and adult physical health. Child Abuse Negl. 2013;37(6):361-73. 